\title{
Compressible extruded granules containing microencapsulated oil powders
}

\begin{abstract}
Gelatine-based dough formulations $(47 \%, 60 \%$ or $70 \% \mathrm{w} / \mathrm{w}$ total solids) with embedded microencapsulated fish oil powders were extruded, dried and compressed to obtain tablets with $35 \%$ w/w oil. The effects of dough total solids and pre-conditioning temperature $(20,35$ or $50{ }^{\circ} \mathrm{C}$ ) prior to extrusion on the amount of oil leakage from the tablets were examined. Oil leakage from tablets was lowest when made from extrudates of dough with $47 \% \mathrm{w} / \mathrm{w}$ TS and pre-conditioned at $35{ }^{\circ} \mathrm{C}$. Increasing dough total solids increased oil leakage. This suggests that adequate hydration of the matrix, necessary for functionalization of the protein, was essential for subsequent tableting performance. The ability to make directly compressible formulations with embedded microencapsulated oil powders broadens the application of spray-dried fish oil powders into the nutritional supplement markets.
\end{abstract}

Keyword: Fish oil; Tablet; Extrusion; Nutraceutical; Nutritional supplement 